\author{
LUIS FELIP LÓPEZ-ESPINOSA \\ Universidad de Málaga \\ felip885@gmail.com
}

\title{
Hegel y la dialéctica de las ideologías (placer, corazón y virtud)
}

\section{Hegel and the dialectics of ideologies (pleasure, heart, virtue)}

RESUMEN:¿Podemos leer la Fenomenología del Espíritu como una teoría de la ideología? Partiendo de lo que Kojève llama la «dialéctica de las ideologías» (placer, corazón, virtud), encontramos no sólo una investigación acerca del papel del deseo en la formación de dichas figuras de la conciencia, sino también una reflexión acerca del modo como concebimos la política en la época moderna. El pensamiento político de Hegel es, aquí, una alternativa a las narrativas moralizantes de la historia. En lugar de ello, debemos sostener la primacía del trabajo y de la praxis en todo proyecto de transformación social.

PALABRAS CLAVE: Hegel; Ideología; Moralidad; Política

\begin{abstract}
Can we read The Phenomenology of Spirit as a theory of ideology? Starting from what Kojève calls the «dialectic of ideologies» (pleasure, heart, virtue), we find not only an investigation into the role of desire in the formation of those figures of consciousness, but also a reflection about the way in which we conceive politics in the modern age. Hegel's political thought is, here, an alternative to moralising narratives of history. Instead, we must stand for the primacy of labour and praxis in every project of social transformation.
\end{abstract}

KEYWORDS: Hegel; Ideology; Morality; Politics 


\section{INTRODUCCIÓN}

$\mathrm{E}$ n su curso de 1935-1936, Alexandre Kojève analiza la posición de lo que denomina, en su peculiar interpretación existencialista y humanista, como el «Hombre-de-la-razón en general» en el Capítulo V, apartado B de la Fenomenología del Espíritu. Según afirma Kojève, éste no es otro que el sujeto del individualismo y del liberalismo burgués. En otras palabras, el sujeto de nuestro tiempo. ${ }^{1}$

Hegel dedicaría, pues, el mencionado pasaje a analizar el proceso de sublimación de los impulsos y de destrucción de las ideologías en la época moderna, toda vez que se ha perdido la inmersión en la substancia ética y toman el protagonismo los individuos, que en sí mismos y por sí solos creen poder alcanzar lo universal. En este artículo comentaremos estos pasajes donde Hegel aborda la «dialéctica de las ideologías» en palabras de Kojève, esto es, el tránsito de las distintas figuras que adopta la conciencia en el devenir de la moralidad: placer, corazón y virtud.

La identificación que hace Hegel de la ideología con la sublimación de los impulsos (Triebe) sigue de plena actualidad. Como veremos, Hegel definirá el goce (jouissance, concepto central del psicoanálisis lacaniano y de la teoría de la ideología de Žižek ${ }^{2}$ ) como motor de las representaciones imaginarias que definen estas distintas figuras de la conciencia. También es crucial la caracterización que hace Hegel de la ideología como aquel pensamiento unilateral, individual y abstracto que tiene su origen en la separación del individuo y la substancia, y por consiguiente en el Yo predominante del subjetivismo y del individualismo burgués. De este modo, Hegel anticipa la noción lacaniana del Yo (moi) imaginario, y la intuición althusseriana del Sujeto como centro de la ideología. La crítica hegeliana de las formaciones ideológicas es también muy actual, porque supera la ingenuidad de las críticas ilustradas, y asume esta alienación fundamental del individuo, la imposibilidad de retornar a la substancia simple e indeterminada, y la vía de la praxis, de la acción social y del trabajo, como realización material de la substancia racional en la historia.

\section{EL INDIVIDUALISMO BURGUÉS Y LA DIALÉCTICA DE LAS IDEOLOGÍAS}

El individuo ilustrado se rebela contra la sociedad, contra las leyes y las costumbres, que son concebidas como lo inesencial, lo abstracto, frente a lo viviente y lo real: el individuo, el Yo. ${ }^{3}$ El individuo en tanto tal identifica el Yo como su verdad, y la búsqueda de la unidad del espíritu es experimentada,

[1] A. Kojève, Introducción a la lectura de Hegel, Madrid: Trotta, 2013, p. 126.

[2] S. Žižek, The sublime object of ideology. London; New York: Verso, 1989.

[3] G.W.F. Hegel, Fenomenología del espiritu, Madrid: Abada, 2010, p. 437. 
subjetivamente, como búsqueda de la dicha, de la felicidad. Lo que realmente es el despliegue del espíritu hacia la autoconciencia, es experimentado como un proceso puramente individual por el ser humano que, a través de su obra y de su acción práctica, se pierde para posteriormente reconocerse en la mundanidad.

Con esto comienza propiamente la experiencia ética del mundo, por la vía de la superación de aquellas formas o figuras que la conciencia racional considera válidos en tanto aislados:

El placer y la necesidad

La ley del corazón y el delirio del engreimiento

La virtud y el curso del mundo

\section{II.1. EL DESEO Y LA NECESIDAD, O EL AMOR DE TRANSFERENCIA}

Según Kojève, el estadio del placer corresponde con el periodo de la Ilustración tal como lo caracteriza Hegel en el capítulo VI. ${ }^{4}$ Para Hegel, este momento deja atrás la substancia ética, la ley; su primer fin sería la autoconciencia, en tanto esencia singular, en el reconocimiento de otra autoconciencia. ${ }^{5}$ Desde el punto de vista de Kojève, en el placer no hay acción: no encontramos ya el trabajo característico del Esclavo, pero tampoco encontramos la lucha del Amo. El individuo volcado hacia el placer es estéril, «no crea su felicidad, sino que la toma y goza de ella tal y como le es dada». ${ }^{6}$ La forma o figura del placer sería la posición subjetiva de la seducción, la del Fausto de Goethe que se entrega al mundo y deja atrás la ley ética y la gris teoría. ${ }^{7}$ En lógica con esto, Hegel caracteriza el estadio del placer como aquel en el cual la autoconciencia tiene como finalidad no alcanzar un objeto, sino ser reconocida en otra autoconciencia.

Pero el goce en este estadío del principio del placer es contradictorio, según Hegel. El deseo persigue un telos, el goce del objeto. Sin embargo, en el goce se supera y cancela el ser individual, éste queda indeterminado porque es intercambiable con cualquier otro y sólo su cualidad de finalidad evanescente es de la incumbencia del sujeto deseante. Hastiado de la carencia de significado que suponen los goces particulares, el libertino cae en el reconocimiento «de su pérdida en la necesidad $»^{8}$ y el autoextrañamiento. Cede aquello que constituye su existencia mundana, contempla su praxis como algo externo. Ahora bien, en

[4] A. Kojève, O. Cit., p. 127.

[5] G.W.F. Hegel, O. Cit., p. 441.

[6] A. Kojève, O. Cit., p. 128.

[7] G.W.F. Hegel, Ibid.

[8] G.W.F. Hegel, O. Cit., p. 447. 
esta alienación de su existencia halla el cobijo de una inmersión más plena en la substancia, «pues esta necesidad o universalidad pura es su propia esencia». ${ }^{9}$

Este movimiento de los goces particulares a la necesidad o universalidad de la propia esencia está en Il catalogo è questo, el famoso aria de Leporello en Don Giovanni. Como afirma Kierkegaard en su análisis de la obra, Leporello es una especie de apéndice de Don Giovanni, en torno a quien giran todos los personajes. Y en el aria de Leporello se condensa la forma en que se relaciona con su amo. Destaca Kierkegaard cómo, en la lectura que lleva a cabo Leporello ante doña Elvira de las sucesivas conquistas de Don Juan, el criado, que comienza a mencionar los datos con serenidad administrativa, va inflamándose y encendiéndose, capturado por lo descomunal de las proezas del seductor. ${ }^{10}$ Esta escena es muy reveladora porque lo que fascina a Leporello no es el goce particular de Don Giovanni (al cual se halla tan entregado a sus relaciones sexuales que necesita de un contable). Lo que fascina a Leporello es el propio listado, la enorme acumulación de nombres, procedencias y extracciones sociales. Se diría que en un momento del aria, la cantidad deviene en cualidad y el listado cobra un protagonismo en sí mismo como objeto de deseo. Este leporelliano deseo por el hecho mismo de desear, en su desplazamiento sucesivo más allá de todo deseo individual y transitorio, hace emerger al propio deseo como substancia última y primer principio de la realidad, como elemento necesario ante la cual los goces particulares son irrelevantes.

Jacques Lacan hablaba de algo similar a lo que alude Hegel cuando trata el paso de la substancia ética al estadío del placer. Cuando el sujeto accede al discurso, afirma Lacan, el Sujeto queda escindido, barrado (\$) por una castración fundamental. Al acceder al universo de discurso, al abandonar la substancia plena, el sujeto debe asumir un mínimo de castración simbólica. Algo se pierde pues de la substancia, si bien tras esta escisión queda un resto, algo que Lacan llama el objeto $a$, y que también denomina, con resonancias marxistas, como plus-de-gozar. ${ }^{11}$ Toda vez que el sujeto renuncia al goce pleno desde el momento en que accede al universo simbólico, retorna como un misterio (Lacan diría

[9] Ibid.

[10] «Baste indicar, sencillamente, la manera reposada y poco movida que tiene al empezar; y cómo va inflamándose todo a medida que resuena más y más en ello la vida de Don Juan; y cómo Leporello, cada vez más extasiado, se eleva y se mece en estos aires eróticos; y, finalmente, cómo crece la sucesión de los diversos matices a medida que se van oyendo las diferencias de la femineidad, que son el repertorio consabido de Don Juan.» S. Kierkegaard, «Los estadios eróticos inmediatos o el erotismo musical», en Kierkegaard (Biblioteca de grandes pensadores), Madrid: Gredos, 2010, p. 244.

[11] J. Lacan, El seminario 16. De un otro al Otro, Barcelona: Paidós, 2008, pp. 15-24. 
que en la dimensión de lo Real) el plus-de-gozar como la pieza que completaría el rompecabezas y por tanto como objeto causante del deseo mismo. ${ }^{12}$

Ante esta situación del sujeto, entre la castración y el deseo de una completud perdida, podemos encontrar dos vías. La vía de Leporello es la de la perversión (y el goce que extrae Leporello de la lectura del listado es precisamente el goce perverso que se sacia negando toda renuncia al deseo y toda castración). Pero no desarrollaremos de momento este tema. La segunda vía, que es la adoptada por Hegel, en la línea de los románticos que la entienden como redención del libertino, es la vía del amor.

El sujeto libertino, a través de la sucesión de goces que demuestran la evanescencia del objeto particular (el libertino desea únicamente el propio deseo) se encuentra ante lo universal. Pero este encuentro pone en grave riesgo la contingencia misma del individuo. Esta conciencia del universal vacío de contenido, que además hace estrellarse lo individual, es lo que Hegel denomina como «necesidad» o «destino». Pero, ¿a qué se refiere Hegel realmente cuando habla del destino?

Para Hegel, necesidad y contingencia no se encuentran en una relación de exclusión, sino en una relación de contradicción dialéctica, donde una remite a la otra. El ser necesario y el ser contingente no constituyen dos grados distintos de realidad, sino que la necesidad brota de la propia contingencia, como un mecanismo de defensa del sujeto, al estilo del mecanismo del reconocimiento-desconocimiento ideológico apuntado por Althusser, ${ }^{13}$ y por medio del cual una idea universal viene a la luz. Así, el vínculo dialéctico entre contingencia y necesidad tiene la forma de la caída, de lo trágico, de la pérdida absoluta del sentido en el curso de una existencia particular, y la recuperación o recomposición del sujeto por medio de una sumisión al destino o un amor fati. Pero, dicho esto, ¿qué es esta conciencia del destino o de la necesidad, que surge al libertino en medio de los goces contingentes y por tanto inauténticos, que se estrellan contra el principio de realidad, sino el amor? El propio Hegel afirmará más adelante en el polémico capítulo sobre la familia de sus Principios de la filosofía del derecho, que el amor es una inclinación que «surge en las personas recíprocamente inclinadas a la unión del amor al reconocer que

[12] «...el advenimiento del sujeto deseante sólo se instituye a partir de su relación con el Otro, quien ordena para él su sujeción al significante. Con el surgimiento del sujeto cautivo de la falta del Otro (S A [A barrada]) cae el objeto a y, en consecuencia, el sujeto sólo lo abordará a través del fantasma: \$ $\diamond$ a» (J. Dor, Introducción a la lectura de Lacan. La estructura del sujeto, Barcelona: Gedisa, 1994, p. 118.)

[13] L. Althusser, «Idéologie et Appareils Idéologiques d'État», en Sur la reproduction, Paris: P.U.F., 1995, pp. 269-314. 
están destinados a ella». ${ }^{14}$ En la cita de Hegel, el peso no deberíamos ponerlo en la idea de predestinación, sino en el proceso subjetivo del reconocimiento que certifica y proporciona validez a un encuentro amoroso. De manera que no es la inclinación amorosa la que determina el reconocimiento, sino que es el mismo reconocimiento, el momento decisorio, el que produce retroactivamente aquella inclinación: en el auténtico amor, llega a afirmar Hegel, «la decisión matrimonial constituye el comienzo y tiene como consecuencia la inclinación». ${ }^{15}$

La superación del goce es por tanto el amor, pero el amor del que habla Hegel es lo que en psicoanálisis recibe el nombre de amor de transferencia en la cura analítica. ${ }^{16} \mathrm{El}$ concepto fue desarrollado en profundidad por Freud, ${ }^{17}$ para dar explicación de un fenómeno que data de los tiempos en que éste y Breuer desarrollaron las investigaciones conducentes a la publicación de los Estudios sobre la histeria. La transferencia surgió en aquellos años iniciales del psicoanálisis en la forma de la declaración de amor de Anna O. hacia Breuer, quien huyó espantado, abandonando a su paciente. Para los psicoanalistas, el amor de transferencia (donde se transfiere al analista la relación del sujeto con sus progenitores ${ }^{18}$ ) es un fenómeno altamente previsible dentro de la cura analítica, y de hecho forma parte de las resistencias al análisis. Es tan previsible, que se considera que a partir de ese momento el análisis se convierte en la indagación sobre un deseo evocado en el transcurso de su propia práctica clínica. ${ }^{19}$

El amor de transferencia, como forma de resistencia, se supone que aparece en ese momento en el cual el análisis ha tocado algún punto traumático. Ante esta incomodidad, el analizante responde, de manera completamente involuntaria, desarrollando una forma de amor hacia su analista que le permitiría sustraerse a sus incómodas indagaciones. De este modo, el amor es la respuesta que vendría a recomponer el sentido de una relación analítica, que ha devenido

[14] G.W.F. Hegel, Principios de la filosofia del derecho, Barcelona: Edhasa, 2005, p. 280.

[15] Ibid.

[16] Para una detallada exposición del papel del amor de transferencia en el mecanismo del reconocimiento ideológico, véase M. Dolar, «Beyond interpellation», Qui Parle, 6: 2 (Primavera-verano de 1993), pp. 75-96.

[17] S. Freud, «La dinámica de la transferencia», en Obras Completas, t. 5, Madrid: Biblioteca Nueva, 2007, pp. 1648-1653 y S. Freud, «Observaciones sobre el amor de transferencia», en Obras Completas, t. 5, O. Cit., pp. 1689-1696.

[18] S. Freud, «La dinámica de la transferencia», O. Cit., p. 1649. Ver también J. Laplanche y J.-B. Pontalis, Diccionario de psicoanálisis, Barcelona: Labor, 1971, p. 462.

[19] «En tanto que las comunicaciones y las ocurrencias del paciente se suceden sin interrupción, no debemos tocar para nada el tema de la transferencia, dejando esta labor, la más espinosa de todas las que se nos plantean en el análisis, para el momento en que la transferencia se haya convertido ya en resistencia» (S. Freud, «La iniciación del tratamiento», en Obras Completas, t. 5, Madrid: Biblioteca Nueva, 2007, p. 1671. 
inquietante. Regresando a Hegel, encontramos la transferencia, ya fuera de la práctica analítica, en el propio encuentro del libertino con el amor (algo que no debe llamarnos la atención, pues el amor de transferencia psicoanalítico tiene tanto de extraordinario y anormal como lo tiene el enamoramiento normal y corriente ${ }^{20}$ ); y esto es también, nuevamente, lo que tenemos en Don Giovanni. Frente al deseo excesivo que vacía de contenido todo deseo particular, el amor por doña Elvira es la recomposición de lo múltiple en lo Uno, la subversión de la pluralidad en la particularidad de un goce que representa el deseo universal.

Este reconocimiento, o este amor de transferencia que supone reconocer y plegarse a la necesidad (forma confusa del reconocimiento de la universalidad) como verdadera esencia de nuestro ser contingente, abre la puerta para la segunda figura de la conciencia ideológica, la «ley del corazón». En el apartado referido a la misma, Hegel dirá que esta ley se enfrenta a la realidad efectiva presentada, precisamente, como necesidad en este primer momento ${ }^{21}$ Contra la alienación ideológica en la necesidad, que no es cualitativamente distinta del reino del principio del placer sino más bien su superación inmanente, la «ley del corazón» será la primera respuesta crítica. Pero según veremos, una respuesta también insuficiente.

\section{II.2. LA LEY DEL CORAZÓN, O LA CRÍTICA HEGELIANA}

\section{A LA INGENUA TEORÍA DE LA IDEOLOGÍA}

El sujeto que quedó desamparado al perder la felicidad del goce pleno, descubre en el estadio del placer la propia contingencia de su ser. Perdido el goce pleno, el sujeto descubre que el mundo es un mundo imperfecto, atravesado por una carencia o por una falta: el goce en el mundo es imposible. Ahora bien, no nos hallamos en este momento aún ante un sujeto capaz de hacer frente a esta falta, sino ante la forma o momento inferior de la ideología. La experiencia de la pérdida de uno mismo en la necesidad es acompañada del amor como defensa o resistencia: alienación en la necesidad, amor fati, o amor a secas (como la afirmación de que la contingencia particular en la que me hallo toma la forma de un destino al que me someto sin otra alternativa). Este vacío, esta carencia de los objetos contingentes, se suple a modo de defensa a través de la transferencia, del amor que se aferra a una particularidad como necesidad o como destino (este es el mecanismo típico de redención del libertino por el amor, desde el Fausto de Goethe al Don Juan de Mozart, quien pasa de la fase estética de construir

[20] S. Freud, «Observaciones sobre el amor de transferencia», O. Cit., p. 1695.

[21] «Esta realidad efectiva que aparece frente a la actual figura de la conciencia no es, como resulta evidente, otra cosa que la precedente relación escindida de la individualidad y de su verdad, la relación de una necesidad cruel por la que aquélla se ve oprimida» (Ibíd., p. 449). 
la universalidad, a partir de la lista de sus amantes, a la superación a través del vínculo necesario con un amor que se representa como eterno).

La segunda figura ideológica es pues la «ley del corazón». Ahora, el individuo sabe que tiene en su interior lo universal: en su corazón alberga una Ley, un "propósito al que la conciencia va a dar realidad efectiva». ${ }^{22}$ Pero a esta ley del corazón se opone una realidad exterior, como alteridad del concepto. Esta alteridad, esta realidad contrapuesta a la realidad que quiere construir el corazón, es una ley externa: el orden del mundo. «Ese orden soberano divino y humano, dado que está separado del corazón, es, a los ojos de éste, una apariencia que debe perder lo que todavía le compete a éste, a saber, el poder violento y la realidad efectiva». ${ }^{23}$ Frente a este orden del mundo, existe una humanidad oprimida que en lugar de servir a la ley del corazón obedece a una necesidad extraña. Por eso la ley del corazón se representa a sí misma como adalid de la gente decente frente a los tiranos y oligarcas, y para su autoconcepto son centrales las ideas de buena voluntad y de amor. ${ }^{24}$

Queda patente, a partir de este enfrentamiento con el poder y la necesidad, la forma perversa de esta ley del corazón, que encuentra placer en el propio proceso de su proyecto político, en el autocumplirse de la ley del corazón, pero no en sus resultados externos y materiales:

Lo que realiza efectivamente es ello mismo la ley, y por tanto, su placer es, a la vez, el placer universal de todos los corazones. Ambas cosas están, a sus ojos, sin separar; su placer es lo que está acorde con la ley, y la realización efectiva de la ley de la humanidad universal es lo que le procura su sólo y singular placer. ${ }^{25}$

De este modo, la ley del corazón es una evolución, incluso una sublimación en términos freudianos, del principio del placer que impulsaba a la primera figura, pero que se estrellaba irremisiblemente contra el principio de realidad. ${ }^{26}$

[22] Ibid., p. 449.

[23] Ibid., p. 451.

[24] Un ejemplo de discurso basado en estos ejes es el de Juan Carlos Monedero en su libro Curso urgente de política para gente decente, Barcelona: Seix Barral, 2013. También encaja en esta línea discursiva su frase, pronunciada y citada en varios lugares: «somos una fábrica de amor» (una idea que ya está en una cita célebre del Che Guevara).

[25] Ibid.

[26] «Es de una agudeza casi freudiana el insinuar que hay una conexión directa entre la (frustración por la) más tosca búsqueda del placer sensual externo y los sublimes sentimientos del corazón a favor del mundo en general, como si en el pasado de quien promueve las más bellas causas desde las palpitaciones de su sensibilidad particular hubiera una etapa completa de frustración en el hedonismo, o como si la sensiblería político-social tuviera mucho de hedonismo 
Ahora bien, añade Hegel, el proyecto del individuo impulsado por la ley del corazón resulta en sí mismo contradictorio. Cuando el individuo realiza la ley del corazón como orden universal, este vuelve a erigirse como algo externo donde no se reconoce, de modo que la realización de la ley del corazón es en sí contradictoria con la propia ley del corazón individual. ${ }^{27}$ Además, para aquella humanidad a la que el individuo intenta emancipar con toda la buena voluntad, la ley del corazón que éste instaura es percibida como ley de otro corazón. ${ }^{28}$ Esta es por consiguiente la doble ruina de la puesta en práctica por el individuo de su ley del corazón.

Todo programa emancipatorio entra en crisis cuando, en lugar de mancharse las manos obrando, busca mantenerse en la pureza, salvar las buenas intenciones. «La individualidad no se ha movido todavía de su sitio, y la unidad de ambos no ha llegado a tener lugar por el movimiento mediador de ellos, por la disciplina». ${ }^{29} \mathrm{El}$ individuo que intenta poner en práctica la ley toma el orden establecido simplemente como lo muerto, y su corazón como lo vivo; sin embargo, puesto que rechaza toda praxis efectiva y todo compromiso práctico, cuando se realiza su proyecto político, la individualidad no se reconoce: opta por consiguiente por un estado izquierdista e infantilista de marginalidad y de oposición permanente.

Según afirma Kojève, en el individuo de la «ley del corazón» existe ya una acción, una negación, si bien en forma de la crítica puramente verbal. Además, aunque niega (critica) la sociedad, él mismo se define a partir de la misma, por lo que para conservarse a sí mismo debe conservar también la sociedad que es objeto de crítica. Cómicamente, Kojève añade cómo «se las arregla para que su crítica no se realice; o bien, si sus críticas se realizan, no se da cuenta de ello y continúa criticando la nueva sociedad». ${ }^{30}$ Teme cambiarse a sí mismo en el transcurso de la transformación revolucionaria de la realidad existente. En este caso, como en el caso del hombre del placer, el sujeto se guía por la autoafirmación de la independencia individual frente al mundo. De ahí que la utopía, como la obra teórica de la ley del corazón, esté ligada a la locura: porque se sitúa en la contradicción perpetua, donde lo irreal es vivido como lo real y a la inversa. ${ }^{31}$ Este aislamiento es también un delirio de grandeza, ${ }^{32}$ una autoafirmación de uno mismo frente al mundo, una voluntad de transformar

sublimado» (Antonio Gómez Ramos, O. Cit., p 139.)

[27] G.W.F. Hegel, Ibid.

[28] Ibid., p. 453.

[29] Ibid., p. 451.

[30] A. Kojève, O. Cit., p. 129.

[31] A. Kojève, O. Cit., p. 130.

[32] Ibid. 
el mundo guiada por el principio del placer: porque el mundo no es mi mundo, «porque yo no estoy a gusto ahí, porque yo no encuentro mi placer ahí». ${ }^{33} \mathrm{De}$ modo que nuevamente, el amor propio y el narcisismo del Yo constituye el centro de esta segunda forma de la ideología burguesa.

Hegel afirma que el desvarío del individuo de la ley del corazón no es sino resultado de la inversión de lo real en irrealidad y de la irrealidad como realidad verdadera. Esta visión de lo individual como la verdad es definida por Hegel como una perversión, la perversión de apostar a la propia utopía, al propio fantasma, antes que a la realidad. ${ }^{34} \mathrm{La}$ arrogancia de persistir en la locura lleva, según Hegel, a proyectar sin embargo este delirio en otros sujetos individuales. ${ }^{35} \mathrm{El}$ utópico delirante interpreta que el mundo no se realiza conforme a su utopía no porque sea contradictoria en sí misma, sino por culpa de los engaños de los curas y de los tiranos. Es así como se erige la crítica ingenua de la ideología, que Hegel interpreta por tanto como insuficiente:

Denuncia, entonces, el orden universal como un orden inventado por clérigos fanáticos, por déspotas atrabiliarios y lacayos suyos que se resarcen de su humillación humillando y oprimiendo, como una inversión de la ley del corazón y de su felicidad, inversión manipulada para la indecible miseria de la humanidad engañada. ${ }^{36}$

Así es como la crítica ilustrada a la ideología atribuye de un modo ingenuo la imperfección del mundo a la corrupción de una minoría, de los «de arriba» (curas y tiranos o, más recientemente, políticos y banqueros).

Pero, si el poder establecido, las leyes vigentes o el orden del mundo no son consecuencia de un plan perverso de una minoría por mantener al pueblo en la oscuridad, ¿en qué consisten? Hegel responde con una afirmación realista y materialista: el poder político no es el resultado de la voluntad utópica de un individuo o de un grupo, sino la correlación de fuerzas entre todos los corazones individuales. El orden público en este periodo de la historia es «resistencia universal y una lucha de todos contra todos en el [sic] que cada uno hace valer su propia singularidad, pero, a la vez, sin llegar a conseguirlo, porque cada uno experimenta la misma resistencia». ${ }^{37}$

[33] Ibid.

[34] «...la autoconciencia se muestra como esta inversión interior de sí misma, como la locura de la conciencia, a la cual su esencia le es inmediatamente inesencia, y su realidad efectiva le es inmediatamente efectiva irrealidad» (G.W.F. Hegel, O. Cit., p. 455.

[35] Ibid., p. 457.

[36] Ibid.

[37] Ibid., p. 459. 
La ideología es, para los ilustrados, un mero engaño de curas y tiranos. Disueltos los lazos sociales que legitiman esta dependencia de unas élites tiránicas, la falsa conciencia ideológica también se disolvería. Los ilustrados han reconocido que existen sistemas de ideas que se imponen a los sujetos como una fuerza material externa, pero creen ingenuamente que acabar con esta imposición devolvería a los individuos a su verdadera naturaleza. Ignoran por tanto la dimensión fundamental de la subjetividad, que se realiza a través de estas ficciones imaginarias constitutivas. Acabar con el engaño de los tiranos sin más no devolvería a los sujetos a su verdadera esencia, sino que los retrotreaería a ese estadio mítico de la substancia ética, la cual, como hemos afirmado anteriormente, no es sino una formación imaginaria retroactiva. Es necesario asumir la alienación fundamental del sujeto en la praxis, como proceso de construcción de la substancia en la historia universal.

Según Hegel, el desvarío de la ley del corazón se supera en el momento en que el individuo reconoce que el orden institucional tiene más realidad, y por tanto más racionalidad, que el orden utópico individual: hay que mancharse las manos. En el proyecto individual reside lo trastornado, y surge entonces la tercera forma de la ideología burguesa, la virtud como renuncia al individualismo o a la particularidad de la conciencia.

\section{II.3. EL «CABALLERO DE LA VIRTUD» O LA INVERSIÓN DE LO UNIVERSAL}

En la forma de la virtud, lo fundamental pasa a ser entonces la ley; la individualidad es el resto que debe superarse y sacrificarse, tanto en su propia conciencia como en el curso del mundo. ${ }^{38}$ Si el narcisismo del Yo es la causa del delirio para el individuo sujeto a la ley del corazón, y es asimismo la responsable de que el poder político sea una correlación de fuerzas de los corazones individuales, el estadio de la virtud propone como solución un antihumanismo práctico: la disciplina de lo universal, que sacrifica la individualidad. Para el «caballero de la virtud», afirma Hegel, la ley es superior a los designios individuales. Aunque lo universal no aparece ya como necesidad muerta e inerte, sino como una necesidad en la conciencia, sin embargo en la realidad esta ley se muestra invertida y es tarea del virtuoso enderezarla. ${ }^{39}$

La acción invididual es, en esta etapa, el principio donde tiene su realidad el movimiento de lo universal. Pero en esa individualidad es posible que nos las veamos con la conciencia de la virtud (que ha de realizar una buena universalidad) o con el curso del mundo, donde lo universal tiene una existencia pasiva gobernada por la libre individualidad, que hace un uso del mismo a su

[38] Ibid., p. 461.

[39] Ibid., p. 463. 
conveniencia, con lo que «también puede ser malempleado para producir una realidad efectiva que es su destrucción». ${ }^{40}$ La razón universal se conduce pues a la autodestrucción cuando el individuo, en lugar de atender a la realización de los fines de la virtud (la buena universalidad) se halla bajo la forma económica y política del liberalismo y de la libre concurrencia, donde cada cual la instrumentaliza según sus fines particulares.

Pero el universal de la virtud es un universal abstracto, no un universal real. ${ }^{41}$ El universal tiene su existencia en la conciencia como telos, como finalidad, y en el mundo como potencialidad que aún no se ha realizado (puesto que en efecto, de lo contrario estaríamos en el reino del bien y la hazaña del virtuoso no sería necesaria). Por eso, el bien que persigue el virtuoso no es una realidad, sino una abstracción cuya forma de existencia se da en la relación entre la virtud y el mundo.

Sin embargo, la buena universalidad se halla en el mundo, aunque sea de forma invertida y como potencialidad; el individuo virtuoso cree posible la unidad, cree posible que en último término la universalidad que es su finalidad surja como un acontecimiento inesperado a partir de las potencialidades del propio curso del mundo. El individuo virtuoso apunta por tanto a este determinismo, según el cual el bien se realizará por sí solo, y su acción individual no es sino la ocasión, las acciones individuales que distraen el curso del mundo mientras acontece la ineluctable venida del bien. El contenido de la lucha es indiferente, porque de lo que se trata es de mantener la lucha misma, porque es del conflicto entre las virtudes o capacidades que persiguen el bien y el curso del mundo que contiene el universal en su interior, de lo que se realiza la buena universalidad en el mundo: «este universal está ya realizado efectivamente y de manera inmediata por el concepto de combate mismo.» ${ }^{42}$

Se pueden dar dos interpretaciones de estos caballeros de la virtud, de un lado a otro del espectro ideológico. Por un lado, la postura del «caballero de la virtud» sería análoga a la del partido revolucionario que mantiene las esencias a la espera de que la revolución acontezca de manera más o menos espontánea mientras mantiene luchas parciales o periféricas. Por otro lado, encontramos espléndidamente reproducido el argumento de Hegel en la crítica de Marx al hegelianismo "de izquierda» (pero realmente conservador) de Bruno Bauer, Edgar Bauer, etc. La posición de la «crítica crítica» sobre la que Marx y Engels ironizaban en La sagrada familia era ese distanciamiento entre el intelectual y la masa, marcado por la piedad que mira desde arriba las miserias y los problemas de las clases populares: «la crítica crítica, por superior que se sepa a la masa,

[40] Ibíd., p. 465.

[41] Ibid., p. 465.

[42] Ibid., p. 467. 
experimenta, sin embargo, por esta masa, una piedad infinita». ${ }^{43}$ La palabra que mejor define esta actitud es condescendencia. Engels resume el estilo de esta postura en un párrafo particularmente paródico:

...la crítica no se transforma en masa para permanecer siendo masa, sino para libertar a la masa de la masa de su naturaleza de masa, es decir, dar a los giros populares de la masa los aires del lenguaje crítico de la crítica crítica. El colmo de la humillación gradual consiste en que la crítica aprenda el lenguaje popular de la masa y transforme esta jerga grosera en cálculo trascendente y trascendental de la dialéctica crítica. ${ }^{44}$

Ahora bien, como podemos ver claramente en ambos ejemplos, el «caballero de la virtud» es inflexible y por ese motivo, su adversario parte con una ventaja decisiva y abrumadora. El caballero de la virtud se halla en lo sólido que no puede ceder en sus posiciones maximalistas («es, a sus ojos, una esencia que no se puede abandonar ${ }^{45}$ ), mientras que el curso del mundo abarca y comprende ese momento y todos los demás. En otros términos, la virtud tiene una esencia, se halla fijada en un momento y en realidades concretas, pero el curso del mundo, el orden establecido, es global, en él «nada es subsistente y absolutamente sagrado, sino que puede arriesgarse a la pérdida de todo y de todos». ${ }^{46}$ Por ese motivo afirma Hegel que la virtud no puede vencer: porque tiene menos realidad; es cierto que el curso del mundo es la inversión de lo inmutable, pero es una inversión real, cuyo producto es más real que la verdad abstracta de la virtud que sólo era verdadera en la conciencia:

El resultado que se desprende de esta oposición, entonces, consiste en que la conciencia deja caer, como quien se despoja de un manto vacío, la representación de un bien en sí que todavía no tuviera realidad efectiva. En su combate, ha hecho la experiencia de que el cursod el mundo no es tan malo como parecía; pues su realidad efectiva es la realidad efectiva de lo universal. Con esta experiencia, caduca el recurso de producir el bien sacrificando la individualidad; pues la individualidad es precisamente la realización efectiva de lo-que-es-en-sí; y la inversión deja de ser vista como una inversión del bien, ya que es más bien, justamente, darle la vuelta al mismo, en cuanto propósito, para dirigirlo hacia la realidad efectiva; el movimiento de la individualidad es la realidad de lo universal. ${ }^{47}$

[43] K. Marx y F. Engels, La sagrada familia, Madrid: Akal, 2013, p. 21.

[44] Ibid., p. 24.

[45] G.W.F. Hegel, O. Cit., p. 469.

[46] Ibid., p. 467.

[47] Ibid., p. 471. 
La virtud no tiene un Yo, pero tiene su centro en una esencia, y tiene su base en realidades históricas concretas donde la virtud se realiza (el movimiento, el partido, el socialismo realmente existente...); el mundo burgués no tiene centro y por ese motivo puede sacrificarlo todo. Asimismo, el mundo burgués es un mundo invertido, pero ese mundo invertido tiene más realidad que el mero mundo pensado.

La posición de Hegel acerca del mundo burgués, que anticipa la realidad de la globalización contemporánea y del «fin de la historia» neoliberal, tiene mucho en cómun con lo que Lacan llama el discurso capitalista. ${ }^{48}$ Para Lacan, el discurso capitalista es circular y omniabarcante, ${ }^{49}$ carece de un punto de ruptura y por ello imposibilita toda "lucha anticapitalista». ${ }^{50}$ Asimismo, esta plenitud de realidad, que puede ceder y sacrificar cualquier particularidad, se manifiesta en el discurso capitalista como un rechazo de la castración, es decir, una negativa a identificar una falta en el gran Otro simbólico (o en los términos hegelianos, en ese "curso del mundo" pleno de sentido y perpetuamente triunfante).

El capitalismo es, para Lacan, una economía libidinal orientada a mantener, a sostener la producción de goce (una negación de la falta en el Otro simbólico). Mientras el amo tradicional es castrador, el discurso capitalista se caracteriza por el mandato de un goce del gran Otro simbólico que no tiene ninguna carencia, ninguna falla. Es el fondo que late tras el obsceno mandato del populismo conservador en la forma de un Donald Trump o de una Marine Le Pen. Contra el psicoanalítico balance del «malestar en la cultura» occidental, el amo contemporáneo propone un giro festivo, un estado de felicidad permanente, a partir de la aceptación de un orden simbólico capitalista caracterizado por la ausencia de castración («todo está permitido») y por la extracción constante de goce.

[48] El concepto del discurso capitalista aparece en la conferencia de Jacques Lacan en la Universidad de Milán en 1972 titulada «Du discours psychanalitique», y se publica por primera vez en la obra Lacan in Italia 1953-1978. En Italie Lacan, Milan: La Salamandra, 1978, pp. 32 55; disponible online en http://ecole-lacanienne.net/wp-content/uploads/2016/04/1972-05-12. pdf $(08 / 2017)$.

[49] «El discurso capitalista le confiere a la realidad una conexión de lugares capturados en un movimiento circular con respecto al cual una lucha directa es un absurdo lógico, un absurdo como luchar contra la Técnica o el rizoma» (Jorge Alemán, Para una izquierda lacaniana, Buenos Aires: Grama, 2010, p. 17.)

[50] Ibid. 


\section{LA TEORÍA HEGELIANA DE LA IDEOLOGÍA COMO FALSA CONCIENCIA}

Y ¿cuál es, para Hegel, el resultado del fracaso en la lucha entre la virtud y el mundo? Hegel contesta que la siguiente etapa es la praxis moderna. En la praxis, la conciencia se desprende de la representación del bien, y reconoce que «el curso del mundo no es tan malo como parecía ${ }^{51}$ pues tiene en sí la realidad de lo universal. Asimismo, se reconcilia con la individualidad que antes pretendía sacrificar y con la importancia de dicha individualidad a la hora de realizar lo que es en sí (pues nada puede hacerse en el mundo sin las pasiones individuales). ¿Nos encontramos entonces, en definitiva, con un giro reaccionario del pensamiento de Hegel, que renuncia a la transformación racional del mundo y se conforma con la forma invertida de racionalidad que es la racionalidad burguesa? Concluimos aquí con un brillante pasaje en el cual se puede encontrar la tesis materialista de la ideología.

Según Hegel, la cínica individualidad, que obra sólo siguiendo su propio interés, obra al mismo tiempo según un propósito universal, aunque ignore completamente esta misma universalidad.

La individualidad del curso del mundo puede muy bien creerse que actúa sólo para sí o egoístamente, en beneficio propio; es mejor que lo que ella se cree, su actividad es, a la vez, algo que es en sí, actividad universal. Cuando actúa egoístamente, entonces no sabe lo que hace, y cuando asevera que todos los hombres actúan egoístamente, tan sólo afirma que ningún hombre tiene conciencia de lo que es la actividad. ${ }^{52}$

Marx defendía esta misma tesis, contra los jóvenes hegelianos que malinterpretaban a Hegel, en una de sus primeras obras filosóficas, La sagrada familia (y en este período Marx había leído precisamente la Fenomenología del espíritu, «cuna de la filosofía hegeliana» $\left.{ }^{53}\right)$ :

La idea ha quedado en ridículo siempre que se ha querido separar del «interés». Es fácil comprender, por otra parte, que todo interés de masa históricamente triunfante ha sabido siempre, al pisar la escena del mundo en forma de «idea» o «representación», trascender de sus verdaderos límites, para confundirse con el interés humano general. Esta ilusión forma lo que Fourier llama el tono de cada época histórica. ${ }^{54}$

[51] G.W.F. Hegel, O. Cit., p. 471.

[52] Ibid., p. 473.

[53] K. Marx, Manuscritos: economía y filosofia, Madrid: Alianza, 1980, p. 187.

[54] K. Marx y F. Engels, O. Cit., p. 106. 
Por esto, los intelectuales «hegelianos» que Marx critica en La sagrada familia son realmente heréticos contra Hegel, cuando insisten en distinguir entre Espíritu (Geist) y Masa. Su posición habría sido identificada por Hegel como ideológica, como la propia de «caballeros de la virtud» que oponen su conciencia abstracta de lo universal al curso del mundo y a los intereses mundanos de una masa pasiva. Más bien al contrario, para Marx, como bien señala Lenin en sus Cuadernos filosóficos, «la concepción de la historia (Geschichtsauffassung) de Hegel implica un espíritu abstracto y absoluto, cuya encarnación es la masa». ${ }^{55}$

De este modo, el hacer individual tiene un valor; pero es un hacer individual que, cuando afirma servir egoístamente a un fin personal, no sabe realmente lo que hace. Y aquí encontramos, en la praxis moderna, la plasmación de la ideología según la había caracterizado Marx en el apartado sobre el fetichismo de la mercancía: los individuos no saben lo que hacen, pero lo hacen. ${ }^{56}$ Cuando actúan siguiendo su propio interés, ignoran que son el soporte de relaciones sociales, o más precisamente, de relaciones sociales de producción. Lenin afirma que la primera aparición de esta idea se sitúa precisamente en $\mathrm{La}$ sagrada familia, en un pasaje acerca del concepto de posesión igualitaria en Proudhon, que hay que leer a la luz de las tesis de Hegel: ${ }^{57}$

...el objeto como ser objetivo del hombre es, al mismo tiempo, la existencia del hombre para el otro hombre, su relación humana con otro hombre, la relación social del hombre con el hombre. ${ }^{58}$

Lo que es una inversión ideológica es la conciencia particular, por parte del individuo, de estar persiguiendo fines egoístas. De este modo, cuando Hegel reafirma la importancia de la individualidad, se refiere a la importancia de la praxis individual pero no de la conciencia, que es en la sociedad burguesa una falsa conciencia, susceptible de engaño acerca de su posición real y de sus condiciones reales de existencia.

Y en esta misma línea, para los pensadores socialistas del siglo XIX, la reflexión no se refería ya al espíritu como algo opuesto a la realidad, como fuente misteriosa de un progreso histórico lineal y mecánico. Al contrario, ya para los primeros socialistas utópicos, de lo que se trataba era de encontrar la causa del movimiento histórico en sus contradicciones y en sus fallas:

[55] V.I. Lenin, «Cuadernos filosóficos», en Obras completas, t. 29, Moscú: Progreso, 1986, p. 20.

[56] K. Marx, El capital, O. Cit., p. 90.

[57] V. I. Lenin, O. Cit., p. 15.

[58] K. Marx y F. Engels, La sagrada familia, O. Cit., p. 62. 
En consecuencia, nos dieron (Fourier) al «progreso» como una fórmula abstracta insuficiente: presumieron (Owen) algún vicio fundamental del mundo civilizado; por eso sometieron los fundamentos reales de la sociedad actual a una crítica incisiva. ${ }^{59}$

En conclusión, la teoría de la ideología no versa sobre las creencias, sino sobre las relaciones reales, que se representan de forma imaginaria, y a veces incluso invertida, en las cabezas de los individuos. $\mathrm{O}$ más propiamente hablando, la teoría de la ideología es parte de una teoría relativa a la historia y el desarrollo histórico de las sociedades y de modo específico de las sociedades bajo el modo de producción capitalista. Ese sentido histórico, el de no poder separar el momento presente (la modernidad capitalista) del momento ideológico (la ideología burguesa) estaba ya en los pasajes de Hegel analizados a lo largo del presente artículo. También se recupera, naturalmente, para el materialismo histórico, que es tanto más fiel a la dialéctica hegeliana en cuanto afirma querer darle la vuelta y ponerla sobre sus pies.

\section{IV.1. Obras de Hegel}

\section{BibliografíA}

- Fenomenología del espíritu, tr. Antonio Gómez Ramos. Madrid: Abada, 2010.

- Fenomenología del espíritu, tr. Manuel Jiménez Redondo. Valencia: Pre-Textos, 2006.

- Principios de la filosofía del derecho. Barcelona: Edhasa, 2005.

\section{IV.2. Obras sobre Hegel}

Gómez Ramos, Antonio: «El devenir de la moralidad: el placer, el corazón y la virtud (comentario al capítulo V.B. de la Fenomenología del espíritu de Hegel)», en Felix Duque (ed.), Hegel: la odisea del espíritu. Madrid: Círculo de Bellas Artes, 2010, pp. 127-149.

KoJève, AleXandre: Introducción a la lectura de Hegel. Madrid: Trotta, 2013.

Valls Plana, Ramón: Del yo al nosotros. Lectura de la Fenomenología del Espíritu de Hegel. Barcelona: PPU, 1994.

\section{IV.3. Otros}

Alemán, Jorge: Para una izquierda lacaniana. Buenos Aires: Grama, 2010.

ATHUSSER, Louis: «Idéologie et Appareils Idéologiques d'État», en Sur la reproduction. Paris: P.U.F., 1995, pp. 269-314.

Dolar, Mladen: «Beyond interpellation», Qui Parle, 6: 2 (Primavera-verano de 1993), pp. 75-96.

DoR, JoËL: Introducción a la lectura de Lacan. La estructura del sujeto. Barcelona: Gedisa, 1994. 
FReUd, Sigmund: «La dinámica de la transferencia», en Obras Completas, t. 5. Madrid: Biblioteca Nueva, 2007, pp. 1648-1653.

: «La iniciación del tratamiento», en Obras Completas, t. 5, O, Cit., pp. 1661-1674.

: «Observaciones sobre el amor de transferencia», en Obras Completas, t. 5, O. Cit., pp. 1689-1696.

KIERKEGAARD, SöREN: «Los estadios eróticos inmediatos o el erotismo musical», en Kierkegaard (Biblioteca de grandes pensadores). Madrid: Gredos, 2010, pp. 146-248.

LACAN, JACQUES: «Du discours psychanalitique», en Lacan in Italia 1953-1978. En Italie Lacan, Milan: La Salamandra, 1978, pp. 32-55. Disponible online en http:// ecole-lacanienne.net/wp-content/uploads/2016/04/1972-05-12.pdf (08/2017).

Aires: Paidós, 2003.

: El seminario, Libro 5. Las formaciones del inconsciente. Buenos

: El seminario 16. De un otro al Otro. Barcelona: Paidós, 2008.

Laplanche, Jean y Pontalis, Jean-Baptiste: Diccionario de psicoanálisis. Barcelona: Labor, 1971.

Lenin, Vladímir Ilich: «Cuadernos filosóficos», en Obras completas, t. 29. Moscú: Progreso, 1986.

MARX, KARL: El capital, Volumen 1. Madrid: Siglo XXI, 1975.

MARX, KARl y ENGELS, Friedrich: La sagrada familia. Madrid: Akal, 2013.

Monedero, JuAn CARlos: Curso urgente de politica para gente decente. Barcelona: Seix Barral, 2013.

ŽIžEK, SlavoJ: The sublime object of ideology. London; New York: Verso, 1989. 